\title{
BIM AND GENETIC ALGORITHM OPTIMISATION FOR SUSTAINABLE BUILDING ENVELOPE DESIGN
}

\author{
Y.-W. LIM ${ }^{1,2}$, H. A. MAJID ${ }^{3}$, A. A. SAMAH ${ }^{3}$, M. H. AHMAD 4 , D. R. OSSEN ${ }^{5}$, \\ M. F. HARUN ${ }^{3} \&$ F. SHAHSAVARI ${ }^{1}$ \\ ${ }^{1}$ Department of Architecture, Faculty of Built Environment, Universiti Teknologi Malaysia (UTM), Malaysia. \\ ${ }^{2}$ Centre for the Study of Built Environment in the Malay World (KALAM), \\ Institute for Smart Infrastructures and Innovative Construction, UTM. \\ ${ }^{3}$ Faculty of Computing, UTM, Malaysia. \\ ${ }^{4}$ Institute Sultan Iskandar, UTM, Malaysia. \\ ${ }^{5}$ College of Architecture Engineering and Design, Kingdom University, Kingdom of Bahrain.
}

\begin{abstract}
Decision-making (DM) at the early building design stages is essential to optimise sustainability performances. Nevertheless, the current methods of optimising building sustainability are complex as they involve multiple design variables and performance objectives. With the development of building information modelling (BIM), complicated buildings can be digitally constructed with precise geometry and accurate information for design optimisation in the early stages of project. Thus, this study explores the use of BIM and Genetic Algorithm (GA) to support DM and optimisation for sustainable building envelope design. To develop a BIM-GA optimisation method, Autodesk Revit template was created to extract data of building envelope from a Base Model (BM). Then, the data were employed to compute overall thermal transfer value (OTTV) and construction cost for BM evaluation and GA optimisation. A hypothetical building was modelled and then analysed using the proposed method as a test case. The BIM-GA optimisation method can address the difficulties of DM on building sustainability in the early design process.
\end{abstract}

Keywords: Autodesk Revit, decision-making, design process, optimisation, overall thermal transfer value.

\section{INTRODUCTION}

The concern of sustainability has been raised in the built environment due to the energy crisis, rapid urbanisation and climate change. Building sector is one of the major contributors to energy consumption and environmental impact. Many studies have looked into the ways to achieve sustainable building design through various passive and active solutions [1, 2]. However, the design decision-making (DM) on sustainable building is a complex process. Therefore, further studies are needed to achieve a higher level of automation in sustainable building design through the application of computational methods.

\subsection{Sustainable building design}

The term 'sustainability' refers to environmental quality, society well-being, and economic stability. In many countries, sustainable building certifications and rating systems have been developed to facilitate the pursuit of sustainability in the building projects such as LEED in the U.S., BREEAM in the UK, Green Mark in Singapore and Green Building Index (GBI) in Malaysia [3]. Nevertheless, the components of sustainability are often in conflicts, and thus, they are very difficult to be integrated into a single green rating system [4].

Studies found that analyses and DM at the early project stages is important to develop the sustainable building designs. Appropriate selection of design options and building materials during the design development will achieve energy efficiency and cost saving [5, 6]. Nevertheless, the current methods of measuring, predicting and optimising the sustainability 
performance of buildings are complex. Various disjointed analyses are required to assess and optimise discrete objectives for different building systems. Thus, the DM process involves multiple design variables and performance objectives which are needed to be considered during schematic design and design development stages [1].

\subsection{Green BIM}

As the building industry explored a higher level of automation in design and construction, building information modelling (BIM) has been adopted to digitally model a complex building for design, analysis, construction and management. 'Green BIM' is then introduced to define the contribution of BIM on the process of achieving green or sustainable building design and construction [7-9].

Numerous studies have been conducted to show how BIM adoption in the early stages of sustainable design would improve the efficiency and effectiveness of the project delivery process $[10,11]$. They found that BIM could reduce the work that was required to evaluate multiple design alternatives in order to improve the sustainability assessment process $[4,12]$. Moreover, Green BIM tools have integrated different processes like thermal, daylighting, energy and computational fluid dynamic (CFD) simulations for building sustainability analysis $[13,14]$. BIM data can be extracted for various sustainability analyses using computational algorithm $[4,15,16]$. Hence, the use of BIM is potential to support DM process to optimise sustainable building design especially in the early design stages.

\subsection{Design optimisation}

Design optimisation is one of the most important contributions of BIM in sustainable design. The BIM workflow for sustainability purposes and the BIM software are available in the market today with two steps: Step 1 is the creation of the basic models using the appropriate inherent BIM software; Step 2 is to export these models to the appropriate BIM-based analysis tools. Surveys of the various BIM software systems and models can also be found in papers and books [17-19].

Oh et al. [15] employed Genetic Algorithm (GA) and Pareto optimality to solve a multicriteria optimal design problem of a BIM-based energy performance simulation model. Machairas et al. [20] remarked that search algorithms in combination with parametric models and dynamic energy simulation software were frequently employed to determine the optimal configurations of several building components including the building envelope. Furthermore, some studies presented optimisation of the thermo-physical properties of the building envelope $[12,21]$ and insulation thickness [22] of the opaque envelope. Curtain wall facade components have also been studied, in particular, carbon emissions during the entire building operation [23].

\subsection{Genetic algorithm}

Genetic Algorithm (GA) was introduced by John Holland in 1975. Holland's GA is one of the four classic paradigms in the artificial evolution study, whereas the other three paradigms are Evolution Strategies by Hans-Paul Schwefel and Ingo Rechenberg in 1964, Evolutionary Programming by Lawrence J. Fogel from 1960 to 1966, and Genetic Programming by John Koza in 1989. Evolutionary evolution process is constituted from evolutionary models based on populations that represent the solution to existing problems [24]. 
In the past, evolutionary algorithms have been applied in searching optimum solutions in many real life problems. GA is one such evolutionary algorithm, which has emerged as a practical, robust optimisation technique and a search method [25]. GA is derived from natural and genetic evolution. It consists of optimisation algorithms, searches and learning process.

GA is selected in this study because it is a kind of search technique that is used to locate or search the exact or approximate solutions. The keyword for GA is an evolution where a better solution is selected after the data have been altered to produce a candidate with a higher fitness value. Compare with other optimisation algorithm such as Ant Colony Algorithm and Cuckoo Optimisation Algorithm, GA is simpler; however, it may take some time to run if there is a large population of input data.

\section{PURPOSE OF THE STUDY, SCOPE AND METHODOLOGY}

This study explores the application of BIM and GA to support DM and optimisation for sustainable building designs in Malaysia. Due to the large number of design variables to be considered in a building design, this study limits the scope within the building vertical envelope or facade design. Besides, this study focuses on DM in design development stage, thus the required BIM Level of Development (LOD) is 300. The objective functions are the envelope Overall Thermal Transfer Value (OTTV) and construction cost. The OTTV is selected because it has a significant impact on the building energy performance, and it is one of the evaluation criteria in Malaysian Standard (MS) 1525:2014 [26]. However, the selection of building envelope materials will directly affect the construction cost. A program that has been written in PHP programming aims to import the data extracted from BIM for optimisation using GA.

The methodology of this study consists of two steps as follows:

1. Development of a BIM-GA optimisation method for building envelope OTTV and construction cost via Revit functionalities and PHP programming

2. Validation of the developed BIM-GA optimisation method via test case

\section{DEVELOPMENT OF BIM-GA OPTIMISATION METHOD FOR BUILDING ENVELOPE DESIGN}

\subsection{Definition of design variables and objective functions}

The OTTV is first introduced by American Society of Heating, Refrigerating and AirConditioning Engineers (ASHRAE). It is commonly used as a control for building measurement, especially envelope design that involves commercial buildings and hotels. Malaysia started to use OTTV method in 1989 when the government made the use of OTTV optional to building industry [27]. Indeed, OTTV is important as it implies the controls of the heat transfer through the building materials. According to MS 1525:2014 [26] and GBI [3], the OTTV of the building envelope for a building has a total air-conditioned area exceeding $1000 \mathrm{~m}^{2}$ that not exceed $50 \mathrm{~W} / \mathrm{m}^{2}$. The equation to calculate OTTV as shown below [26]:

$$
O T T V i=15 \alpha(1-W W R) U w+6(W W R) U f+(194 * O F * W W R * S C)
$$

where,

WR: The window-to-gross exterior wall area ratio for the orientation under consideration;

$\alpha$ : The solar absorptivity of the opaque wall; 
Uw: The thermal transmittance of opaque wall $\left(\mathrm{W} / \mathrm{m}^{2} \mathrm{~K}\right)$;

Uf: The thermal transmittance of fenestration system $\left(\mathrm{W} / \mathrm{m}^{2} \mathrm{~K}\right)$;

OF: The solar orientation factor; as in MS1525;

SC: The shading coefficient of the fenestration system;

The OTTV is influenced by the choice of building envelope materials including wall types and window types. In addition, the selection of building envelope materials will also affect the construction cost. Therefore, there is always a conflict in achieving lower OTTV and construction cost saving. Hence, construction cost is selected as the second objective function for the optimisation. The following equation is employed to calculate the construction cost:-

$$
C=C \text { win } * N \text { win }+C w^{*} A w
$$

where,

$\mathrm{C}_{\text {win }}$ : Cost of window per unit;

$\mathrm{N}_{\text {win }}$ : Number of window units;

$\mathrm{C}_{\mathrm{w}}$ : $\quad$ Cost of wall per $\mathrm{m}^{2}$;

$\mathrm{A}_{\mathrm{w}}$ : $\quad$ Area of wall

\subsection{Revit template and PHP programming}

In this study, Autodesk Revit was employed as a BIM authoring tool. By using the Revit functionality of schedule, the required data can be extracted. A Revit Template was created with customised schedules to quantify the variables for OTTV and construction cost calculations. Then, these schedules can be exported as .txt files.

A web-based program was written using PHP to import the .txt files. The imported data can be stored in database as the library of wall types and window types with their properties. Besides, the geometrical data of the model from Revit will be used for Base Model (BM) Evaluation. The BM Evaluation will give the OTTV performance and construction cost of the current design which is modelled in Revit. Then, the user can select the types of wall and window from the database for optimisation using GA.

\subsection{GA setting}

In the process of solving the optimisation problem using GA, the initial step before executing the GA is a generation of the chromosome that likes the representation of wall and window combinations. Data for this combination are taken from the Revit schedules to identify the types of wall and window; the users may use them in the project. After generating the number of all combinations, the system will generate a string representation of the combinations.

In determining a fitness function, the system uses the OTTV calculation as the fitness benchmark. The system will calculate OTTV for each set along with their cost. In this case, the only constraint is that OTTV cannot be more than $50 \mathrm{~W} / \mathrm{m}^{2}$ according to MS1525:2014. When the fitness function of the population is determined, the system will sort the results in an ascending order which is from the lowest OTTV value to the highest one. All the GA steps are the back end programming.

\subsection{Decision-making and documentation}

After running the GA optimisation based on building orientations, the program will plot the solutions in a graph for the user (designer or architect) to choose the appropriate optimum 
solution set for each orientation. Subsequently, the user can compare the performance of the chosen optimum solution with the BM evaluation to search the most appropriate solution according to the design priority (OTTV or cost). Finally, a report can be generated to show the comparison of optimised design with the BM design. The overall workflow of the BIM-GA optimisation method is illustrated as in Fig. 1.

\section{TEST CASE}

In this study, a hypothetical building as shown in Fig. 2a is modelled as BM using Revit with consideration of tropical climate in Malaysia to test and to validate the BIM-GA optimisation method. It is a four-storey height building with windows on each orientation. Using Revit Material Library, it is possible to insert every type of walls and windows into the project as the initial population. From wall and window schedules (Fig. $2 \mathrm{~b}$ and c), all required information such as size, type, area, R-value, U-value, $\alpha$, OF, SC, WWR and even unit cost and total cost can be extracted to run the optimisation process. The optimisation tool helps the decision maker to select the best possible option after comparing OTTV and cost of each combination that produces the optimal sets.

After selecting the types of walls and windows from the library, the GA optimisation was run to generate the solutions. A graph with OTTV against the construction cost was plotted for each orientation by the PHP program as shown in Fig. 3a. Then, the user chose the optimum solution set for each orientation in order to obtain the overall optimisation results. Finally, a report was generated to summarise the results of optimum set for each orientation and total reduction of OTTV and cost. As shown in Fig. 3b, the optimised design was able to reduce the OTTV from $38.385 \mathrm{~W} / \mathrm{m}^{2}$ to $36.611 \mathrm{~W} / \mathrm{m}^{2}$ (which was $4.62 \%$ of reduction), whereas the construction cost was also decreased to $6.22 \%$, which was from RM146, 326.05 to RM137, 227.65 .

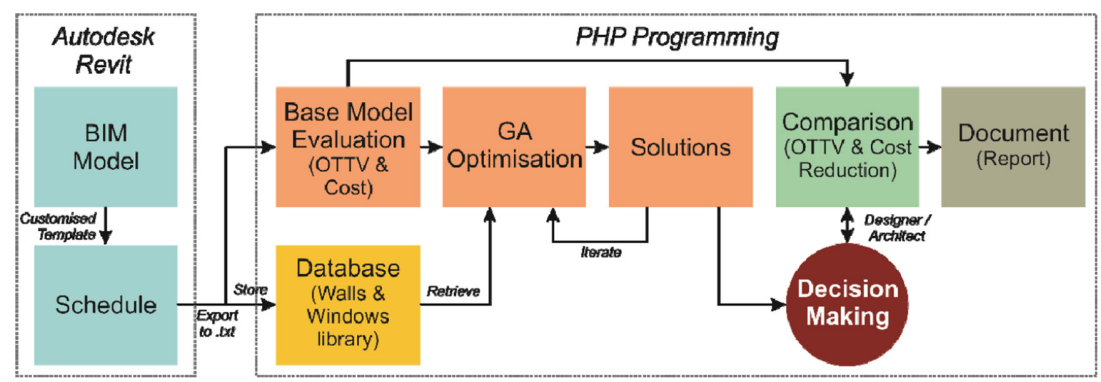

Figure 1: Workflow of the proposed BIM-GA optimisation method.

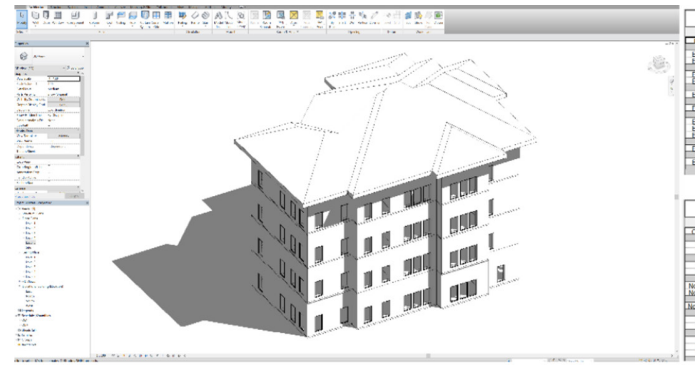

(a)

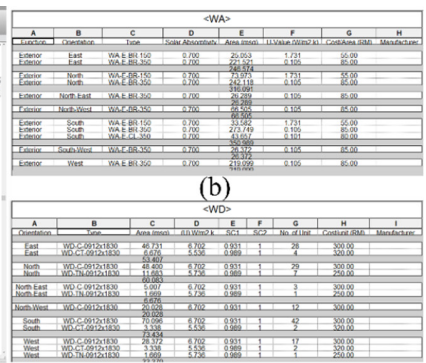

(c)

Figure 2: Base Model in Revit: (a) 3D view; (b) Wall schedule; (c) Window schedule. 


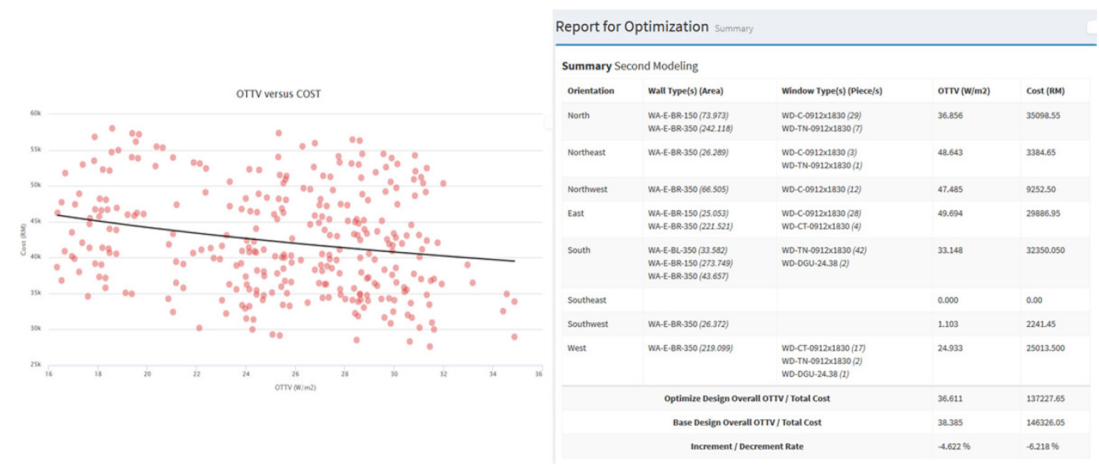

(a)

(b)

Figure 3: (a) OTTV-cost graph; (b) Optimisation results summary.

Table 1: Comparison between manually calculated and the program computed values of OTTV and cost for the optimised design.

\begin{tabular}{lllll}
\hline \multirow{2}{*}{ Orientation } & \multicolumn{4}{l}{ Manually calculated } \\
OTTV $\left(\mathrm{W} / \mathrm{m}^{2}\right)$ & OTTV $\left(\mathrm{W} / \mathrm{m}^{2}\right)$ & $\begin{array}{l}\text { Manually calcu- } \\
\text { lated cost }(\mathrm{RM})\end{array}$ & $\begin{array}{l}\text { Program com- } \\
\text { puted cost }(\mathrm{RM})\end{array}$ \\
\hline North & 36.847 & 36.856 & $35,098.55$ & $35,098.55$ \\
North East & 48.643 & 48.643 & 3384.65 & 3384.65 \\
North West & 47.485 & 47.485 & 9252.93 & 9252.50 \\
South & 33.148 & 33.148 & $32,350.05$ & $32,350.05$ \\
South East & 0.000 & 0.000 & 0.00 & 0.00 \\
South West & 1.103 & 1.103 & 2241.62 & 2241.45 \\
East & 49.694 & 49.694 & $29,887.20$ & $29,886.95$ \\
West & 24.933 & 24.933 & $25,013.50$ & $25,013.50$ \\
Overall & 36.609 & 36.611 & $137,228.49$ & $137,227.65$ \\
\hline
\end{tabular}

In order to evaluate the reliability of the PHP program in calculating and optimising OTTV and construction cost, a comparison was made between manually calculated and the PHP program computed results for the optimised design as shown in Table 1. The results show that there were minor discrepancies between the two calculations $(0.005 \%$ for OTTV and $-0.001 \%$ for construction cost) mainly due to the different uses of decimal points. Hence, the PHP program is reliable to compute the calculations.

\section{DISCUSSION AND CONCLUSION}

DM on sustainable building design is a complex process. The efforts to analyse and optimise building sustainability require a great deal of consideration regarding the varied facets and requirements, which will be very time and cost consuming. Therefore, a higher level of automation in the sustainable building design DM is needed to facilitate the building industry to achieve sustainability. The use of BIM and computational algorithm is a potential solution to support the DM. 
This research has explored the possibility for the higher level of automation in sustainable building design through the application of BIM and GA. It has also proposed a new BIM-GA optimisation method, which consists of new workflow, Revit template and GA optimisation tool in PHP programming. The output of this study addresses the difficulties of DM in the early design process and allows for specific sustainability trade-off analyses to be conducted. Nevertheless, this optimisation is mainly to support the designer or architect for DM rather to provide an absolute solution.

The newly proposed BIM-GA optimisation method only includes OTTV and construction cost as the objective functions. Using the similar method, it can be further developed as a comprehensive integrated BIM-GA optimisation tool for different design variables and objective functions. Furthermore, the tool can be further developed using other multi-objective optimisation algorithms.

\section{ACKNOWLEDGEMENT}

The authors would like to acknowledge the research funding by Universiti Teknologi Malaysia (UTM), Ministry of Higher Education, Malaysia (MOHE) through Fundamental Research Grant Scheme (FRGS), project no. 4F665, titled "BIM-GBI Model Development: Integrating Building Information Modelling and Green Building Certification in Malaysia" and Ministry of Science, Technology and Innovation, Malaysia (MOSTI) through Science Fund, project no. 4S106, titled "BIM-based Process-driven Decision-making for Sustainability".

\section{REFERENCES}

[1] Lim, Y.W., Shahsavari, F., Noor Fazlenawati, M.N.A., Ossen, D.R. \& Ahmad, M.H., Developing a BIM-based process-driven decision-making framework for sustainable building envelope design in the tropics. WIT Transaction on the Built Environment, 149, pp. 531-542, 2015. https://doi.org/10.2139/ssrn.2663945

[2] Nielsen, A.N., Jensen, R.L., Larsen, T.S. \& Nissen, S.B., Early stage decision support for sustainable building renovation - A review. Building and Environment, 103, pp. 165-181, 2016. https://doi.org/10.1016/j.buildenv.2016.04.009

[3] GBI, Green Building Index (GBI) assessment criteria for non-residential new construction (Version 1.0), GBI: Malaysia, 2009.

[4] Bank, L.C., McCarthy, M., Thompson, B.P. \& Menassa, C.C., Integrating BIM with system dynamics as a decision-making framework for sustainable building design and operation. Proceeding of the 1st International Conference On Sustainable Urbanization (ICSU 2010), Hong Kong, China, pp. 15-17, 2010.

[5] Méndez Echenagucia, T., Capozzoli, A., Cascone, Y. \& Sassone, M., The early design stage of a building envelope: Multi-objective search through heating, cooling and lighting energy performance analysis. Applied Energy, 154, pp. 577-591, 2015. https://doi.org/10.1016/j.apenergy.2015.04.090

[6] Schlueter, A. \& Thesseling, F., Building information model based energy/exergy performance assessment in early design stages. Automation in Construction, 18, pp. 153-163, 2009. 
[7] Kriegel, E. \& Nies, B., Green BIM: Successful Sustainable Design with Building Information Modeling, Indianapolis: Wiley Publishing, 2008.

[8] Oduyemi, O. \& Okoroh, M., Building performance modelling for sustainablebuilding design. International Journal of Sustainable Built Environment, 5(2), pp. 461-469, 2016.

https://doi.org/10.1016/j.ijsbe.2016.05.004

[9] Ilhan, B. \& Yaman, H., Green building assessment tool (GBAT) for integrated BIMbased design decisions. Automation in Construction, 70, pp. 26-37, 2016.

https://doi.org/ 10.1016/j.autcon.2016.05.001

[10] Lim, Y.W., Eka, S., Fatemeh, S. \& Noor Fazlenawati, M.N.A., Building information modelling for building energy efficiency evaluation integration with Green Building Index (GBI) in Malaysia. In 4th Annual International Conference on Architecture and Civil Engineering (ACE 2016), Singapore, pp. 42-48, 2016.

[11] Jalaei, F. \& Jrade, A., Integrating building information modeling (BIM) and LEED system at the conceptual design stage of sustainable buildings. Sustainable Cities and Society, 18, pp. 95-107, 2015. https://doi.org/10.1016/j.scs.2015.06.007

[12] Gossard, D., Lartigue, B. \& Thellier, F., Multi-objective optimization of a building envelope for thermal performance using genetic algorithms and artificial neural network. Energy and Buildings, 67, pp. 253-260, 2013.

https://doi.org/10.1016/j.enbuild.2013.08.026

[13] Azhar, S. \& Brown, J., BIM for sustainability analyses. International Journal of Construction Education and Research, 5(4), pp. 276-292, 2009. https://doi.org/10.1080/15578770903355657

[14] Lim, Y.W., Building information modeling for indoor environmental performance analysis. American Journal of Environmental Science, 11(2), pp. 55-61, 2015. https://doi.org/10.3844/ajessp.2015.55.61

[15] Oh, S., Kim, Y., Park, C. \& Kim, I., Process-driven BIM-based optimal design using integration of EnergyPlus, Genetic Algorithm, and Pareto Optimality. In 12th Conference of International Building Performance Simulation Association, Sydney, pp. 14-16, 2011.

[16] Chen, L. \& Pan, W., BIM-aided variable fuzzy multi-criteria decision making of low-carbon building measures selection. Sustainable Cities Society, 27, pp. 222-232, 2016.

https://doi.org/10.1016/j.scs.2016.04.008

[17] Azhar, S., Carlton, W.A., Olsen, D. \& Ahmad, I., Building information modeling for sustainable design and LEED® rating analysis. Automation in Construction, 20(2), pp. 217-224, 2011.

https://doi.org/10.1016/j.autcon.2010.09.019

[18] Crawley, D.B., Hand, J.W., Kummert, M. \& Griffith, B.T., Contrasting the capabilities of building energy performance simulation programs. 9th International IBPSA Conference, 43, pp. 231-238, 2005.

[19] Kymmell, W., Building Information Modeling: Planning and Managing Construction Projects with 4D CAD and Simulations. McGraw Hill Professional, 2007.

[20] Machairas, V., Tsangrassoulis, A. \& Axarli, K., Algorithms for optimization of building design: A review. Renewable Sustainable Energy Review, 31, pp. 101-112, 2014. https://doi.org/10.1016/j.rser.2013.11.036 
[21] Jiang, F., Wang, X. \& Zhang, Y., Analytical optimization of specific heat of building internal envelope. Energy Conversion and Management, 63, pp. 239-244, 2012. https://doi.org/10.1016/j.enconman.2012.01.038

[22] Daouas, N., A study on optimum insulation thickness in walls and energy savings in Tunisian buildings based on analytical calculation of cooling and heating transmission loads. Applied Energy, 88(1), pp. 156-164, 2011. https://doi.org/10.1016/j.apenergy.2010.07.030

[23] Rapone, G. \& Saro, O., Optimisation of curtain wall façades for office buildings by means of PSO algorithm. Energy and Buildings, 45, pp. 189-196, 2012. https://doi.org/10.1016/j.enbuild.2011.11.003

[24] Herrera, F. \& Lozano, M., Adaptation of genetic algorithm parameters based on fuzzy logic controllers. Genetic Algorithms and Soft Computing, pp. 95-125, 1996.

[25] Sharma, C., Sabharwal, S. \& Sibal, R., A survey on software testing techniques using genetic algorithm. International Journal of Computer Science Issues, 10(1), pp. 381-393, 2013.

[26] Department of Standards Malaysia, Malaysian Standard 1525:2014 - Energy efficiency and use of renewable energy for non-residential buildings - Code of practice (2nd revision). 2014.

[27] Vijayalaxmi, J., Concept of overall thermal transfer value (OTTV) in Design of building envelope to achieve energy efficiency. International Journal of Thermal and Environmental Engineering, 1(2), pp. 75-80, 2010.

https://doi.org/10.5383/ijtee.01.02.003 